\title{
Marchandiomyces lignicola sp. nov. shows recent and repeated transition between a lignicolous and a lichenicolous habit
}

\author{
Paula T. DePRIEST ${ }^{1}$, Masoumeh SIKAROODI ${ }^{2}$, James D. LAWREY ${ }^{3}$ and Paul DIEDERICH ${ }^{4}$ \\ ${ }^{1}$ Botany Section, United States National Herbarium, National Museum of Natural History, Smithsonian Institution, \\ P.O. Box 37012, Washington, DC 20013-7012, USA. \\ ${ }^{2}$ Department of Environmental Science and Policy, George Mason University, Fairfax, Virginia 22030-4444, USA; and Botany \\ Section, United States National Herbarium, National Museum of Natural History, Smithsonian Institution, P.O. Box 37012, \\ Washington, DC 20013-7012, USA. \\ ${ }^{3}$ Department of Environmental Science and Policy, George Mason University, Fairfax, Virginia 22030-4444, USA. \\ ${ }^{4}$ Musée national d'histoire naturelle, 25 rue Munster, L-2160 Luxembourg, Luxembourg. \\ E-mail: depriest.paula@nmnh.si.edu
}

Received 21 December 2002; accepted 10 September 2004.

The anamorphic basidiomycete genus Marchandiomyces presently includes two common lichenicolous (lichen-inhabiting) species, M. corallinus and M. aurantiacus (teleomorph Marchandiobasidium aurantiacum). We describe here a new species, M. lignicola sp. nov., that is similar to M. corallinus in the colour of its sclerotia, but differs in having a wood-inhabiting (lignicolous) habit. The phylogenetic position of this lignicolous fungus was compared with the lichenicolous species of Marchandiomyces and related species currently placed in the basidiomycetous families Corticiaceae and Ceratobasidiaceae using parsimony, likelihood, and Bayesian analyses of complete sequences of the nuclear small subunit and internal transcribed spacers ribosomal DNA, and a portion of the nuclear large subunit ribosomal DNA. These DNA sequences were obtained from isolated cultures of freshly collected specimens. Significant Bayesian posterior probabilities, as well as maximum likelihood and parsimony analyses, indicate that the new lignicolous species is closely related to $M$. corallinus, the type species of Marchandiomyces. In most analyses these two species are monophyletic with the lichenicolous $M$. aurantiacus, although this relationship is not strongly supported. Since $M$. lignicola is more closely related to $M$. corallinus than to $M$. aurantiacus, either a transition to the lignicolous habit occurred recently within an ancestral lichenicolous group or, more likely, transition to the lichenicolous habit arose recently and in parallel from an ancestral lignicolous habit.

\section{INTRODUCTION}

Fungi, as heterotrophic organisms, have evolved the ability to degrade and metabolize a diversity of living and non-living organic substrates. Closely related fungi may use different substrates and distantly related fungi may use the same substrates, suggesting that evolutionary transitions among habits occur continuously. Despite this evolutionary flexibility, taxonomists have often emphasized substrate or 'host' habit as a key character when separating otherwise similar fungi. Similarities or differences in habit also have been used as a predictor of evolutionary trends, transitions, and relationships. For some habits, such as the lichenicolous habit where fungi form obligate associations with lichens, it is difficult to predict evolutionary trends and relationships. The lichenicolous fungi represent a phylogenetically diverse assemblage of fungi, but only a few genera contain both lichenicolous and non-lichenicolous fungi linked on the basis of their morphologies. For example, the ascomycete genera Lichenopeltella and Odontotrema have both lichenicolous and non-lichenicolous members. The large genus Arthonia also includes ecologically diverse species, including lichenized, lichenicolous and wood-inhabiting groups. Nevertheless, most genera with lichenicolous species are exclusively lichenicolous and some that are known only as anamorphs (asexual stages) with limited taxonomic characters are defined at least partly by their association with lichens. In the absence of strong morphological evidence, it has been uncommon to place these lichenicolous fungi in genera of mixed ecological habits. We believe that such mixed genera are of special interest, however, since they permit an examination of fine scale evolutionary transitions to and from a lichenicolous habit. 
The most recent survey of these fungi by Lawrey \& Diederich (2003) lists over 1500 known species, with an estimate of over 3000 . More than $95 \%$ of these species are ascomycetous, although a number of distinct basidiomycetous groups have this habit as well (Sikaroodi et al. 2001). Lichenicolous fungi form a myriad of obligate associations where the lichen host is a source of fixed carbon (Hawksworth 1982a, b, 1988a, b). The lichen host, itself a symbiosis of fungi and algae or cyanobacteria, may be clearly and even virulently parasitized with obvious lesions or discolourations. In other cases the lichenicolous fungi, relatively nonaggressive and commensalistic, may cause no apparent damage to their hosts. Other lichenicolous fungi are obligately saprophytic and colonize only dead host tissues. In other cases, 'lichenicolous lichens' may colonize a particular lichen host and simultaneously maintain their own algal symbionts.

Several authors have discussed the evolution of the lichenicolous habit and speculated on possible evolutionary trends. Hawksworth (1978, 1982a, b, 1988a, b) emphasized in numerous publications the reticulate nature of fungal habits including the lichenicolous habit, an hypothesis now supported by phylogenetic reconstructions of transitions among nutritional modes in major fungal clades of ascomycetous (e.g. Gargas et al. 1995) and basidiomycetous fungi (e.g. Hibbett, Gilbert \& Donoghue 2000). Lutzoni, Pagel \& Reeb (2001) went so for as to hypothesize that the lichenicolous habit was for lichenized ascomycetes a first step in loss of the lichen habit. As the latter study proposed that many major clades of ascomycetes were derived from lichen-forming fungi, the initial transition from a lichen-forming to lichenicolous habit would be a critical one. Since the vast majority of described lichenicolous fungi are ascomycetes, there is the potential for repeated evolutionary transitions.

In contrast, the basidiomycetes include few lichens, but many saprotrophic, parasitic and mutualistic (mainly mycorrhizal) species. There are also lichenicolous basidiomycetes from a variety of groups. Our recent phylogenetic analysis (Sikaroodi et al. 2001) demonstrated that a small number of morphologically similar lichenicolous fungi represented at least five diverse lineages of fungi, none of which was closely related to lichen-forming fungi. One of these lineages included two species of basidiomycete lichenicolous fungi, Marchandiomyces corallinus and M. aurantiacus $M$. corallinus parasitizes a variety of living lichens, especially members of the Parmeliaceae. This species is one of the most common lichenicolous fungi in the eastern USA, where it is locally abundant as a parasite of the ubiquitous Flavoparmelia baltimorensis. Infected lichens exhibit obvious coral-coloured sclerotia clustered on the surface of the thallus. The second species, $M$. aurantiacus, includes populations similar in appearance to $M$. corallinus but with lighter orange sclerotia. Recently Diederich, Schultheis \& Blackwell (2003) described the ceratobasidiales-like teleomorph of this species as Marchandiobasidium auranticacum. The anamorph of this species is common in polluted habitats in Europe, where it attacks a variety of lichens, especially species of Physcia. On the basis of phylogenetic analysis of nuclear small subunit (nuSSU) rDNA, these two species form a clade within a larger group that contains some representative members of the basidiomycetous orders Stereales, Poriales, and 'Aphyllophorales', and the ceratobasidialean anamorph Rhizoctonia zeae (teleomorph Waitea circinata). The presumed close relationships between Marchandiomyces and other mitosporic genera (Hobsonia, Illosporium), discussed at various times in the literature (Lowen et al. 1986), were shown to be erroneous, as predicted by Etayo \& Diederich (1996). It should be noted that the most recent edition of the Dictionary of the Fungi (Kirk et al. 2001) says that Marchandiomyces is an anamorphic ascomycete, citing Sikaroodi et al. (2001); this is a mistake since we demonstrated an unambiguous basidiomyetous position for Marchandiomyces.

Recently, non-lichenicolous, apparently lignicolous, marchandiomyces-like fungi were discovered in Virginia (ATCC MYA-299; Sikaroodi et al. 2001). Since the phylogenetic position of Marchandiomyces was clearly established in our previous study, we used similar molecular data to determine if and how these specimens were related to known Marchandiomyces species. Depending on the nature of this relationship, the lignicolous (wood-inhabiting) habit could be either ancestral or derived relative to the lichenicolous habit. We collected specimens and produced cultured isolates of the lignicolous marchandiomyces-like fungus and M. corallinus, and obtained a culture of M. aurantiacus from Toen Boekhout (CBS). These cultures were used to obtain complete nucleotide sequences of the nuclear small subunit and the internal transcribed spacer (nuITS) rDNA, and partial sequences of the nuclear large subunit (nuLSU), information that permitted an examination of the phylogenetic position. Our objectives were to: (1) determine whether the lignicolous specimens are members of the existing Marchandiomyces clade; (2) compare all of these taxa with regard to ecological, anatomical, and morphological characters; and (3) interpret this nonlichenicolous habit as derived or ancestral to the lichenicolous habit.

\section{MATERIALS AND METHODS}

\section{Isolation of fungal cultures}

Three taxa were chosen for study, Marchandiomyces corallinus, M. aurantiacus, and the putative lignicolous Marchandiomyces sp. (ATCC MYA-299 and MYA835) (Table 1). All fungal cultures were isolated from freshly collected material or obtained from collections. Those cultures isolated in our laboratory were obtained using the following protocol. 
Table 1. Marchandiomyces cultures used for DNA analysis.

\begin{tabular}{|c|c|c|c|}
\hline Species & Culture & Source & Host \\
\hline M. aurantiacus & $\begin{array}{l}\text { CBS } 718.97 \\
\text { (T. Boekhout) }\end{array}$ & Luxembourg, 1997, P. Diederich 12365 & Physcia tenella \\
\hline M. corallinus & ATCC 200796 & USA: MD, 1995, J. D. Lawrey 1619 & Flavoparmelia baltimorensis \\
\hline M. corallinus & ATCC MYA-1118 & Scotland, Isle of Mull. 1999, M. Cullen \& H. Fox 216 & Pertusaria amara \\
\hline M. corallinus & JL128-98 & USA: MO, 1997, M. S. Cole 7500 & F. baltimorensis \\
\hline M. lignicola & ATCC MYA-299 & USA: VA, 1997, J. D. Lawrey 1636 & Fallen dead branch \\
\hline M. lignicola & ATCC MYA-835 & USA: VA, 1999, J. D. Lawrey 1716 (holotype) & Fallen dead branch \\
\hline
\end{tabular}

Infected thalli were washed briefly in sterile water, and sclerotia were removed using a flamed needle. Some specimens were surface sterilized with ethanol. Sclerotia were placed on either potato dextrose agar (PDA) or Sabouraud's medium with dextrose (SDA), and mycelial outgrowths were subcultured monthly. Voucher cultures of new isolates were sent to the American Type Culture Collection (ATCC) for deposit.

\section{Anatomical studies}

Dry herbarium specimens were examined microscopically with a Zeiss binocular microscope at 40X and 80X (Diederich 1996). Entire unsectioned sclerotia were examined in water, $\mathrm{KOH}$, lactophenol Cotton blue (LCB), Phloxin after KOH-pretreatment, or Congo red, either without pressure or with slight pressure on the coverslip to visualize hyphal orientation. Macroscopic photographs of sclerotia were prepared using a specially constructed adapter on a compound microscope (Diederich 1996).

\section{DNA extraction}

Total DNA was extracted from each of the cultures using the TES extraction protocol, modified from Grube et al. (1995). Fungal tissue was ground in TES buffer (100 mм Tris, 10mm EDTA, $2 \%$ SDS, pH 8.0), with $1.4 \mathrm{M} \mathrm{NaCl}$ and $10 \% \mathrm{CTAB}$, and extracted twice with 1 volume chloroform:isoamyl (24:1). DNA was precipitated in 0.6 volume of isopropanol with sodium acetate and then washed with $70-80 \%$ ethanol. The DNA pellet was suspended in 20-30 $\mu$ l of deionized water, and the DNA was quantified by visualizing with ethidium bromide on a $1 \%$ agarose gel.

\section{PCR amplification}

Dilutions of the DNA stocks were used for PCR amplifications of portions of (A) the nuSSU, (B) nuITS, and (C) nuLSU. All of the primers used in this study are the same as those listed in Sikaroodi et al. (2001). Three regions of nuSSU rDNA were amplified: (1) the region between primer nu-SSU-0072-5', corresponding to nucleotides 0054 to 0072 of Saccharomyces cerevisiae (Rubtsov et al. 1980, Mankin, Skryabin \& Rubtsov 1986), and primer nu-SSU-0852-3', nucleotides 0871 to 0852, (2) the region between primer nu-SSU-0819-5', nucleotides 0802 to 0819 , and primer nu-SSU-1293-3', nucleotides 1312 to 1293 , and (3) the region between primer nu-SSU-1203-5', nucleotides 1184 to1203, and primer nu-SSU-1750-3', nucleotides 1769 to 1750 . The nuITS region was amplified between primer nu-SSU1766-5' (ITS5), nucleotides 1744 to 1766, and primer ITS4, nucleotides 41 to 60 of the nuLSU rDNA of Saccharomyces cerevisiae (Georgiev et al. 1981).

These fragments were amplified from the genomic DNA ( 10 ng) using 1.25 units of Klentaq 1 (Ab peptides, St Louis, Mo) in $100 \mu \mathrm{l}$ PCR reactions in a reaction buffer $(10 \mathrm{~mm}$ Tris $\mathrm{pH} 8.3,50 \mathrm{~mm} \mathrm{KCl}$ and $2 \mathrm{mM} \mathrm{MgCl}_{2}$ ), with $200 \mu \mathrm{M}$ of each of the four dNTPs and $0.5 \mu \mathrm{M}$ of each primer. The reactions were carried out in a Perkin-Elmer Cetus DNA Thermal Cycler for 30-35 cycles with the following conditions for most of the reactions: template denaturation at $94{ }^{\circ} \mathrm{C}$ for $1 \mathrm{~min}$, primer annealing at $50^{\circ}$ for $1 \mathrm{~min}$, and primer extending at $72^{\circ}$ for 2 min (extended by $5 \mathrm{~s}$ in each cycle). The PCR products were purified of excess primers using either of two protocols: (1) by precipitation with $20 \%$ polyethylene glycol (PEG) and $2.5 \mathrm{~mol} \mathrm{~L}^{-1} \mathrm{NaCl}$, or (2) by filtration through PCR Wizards (Promega, Madison, WI) following the manufacturer's instructions. The concentration and size of the PCR amplification products were estimated by comparing them to nucleotide weight and size markers after agarose gel electrophoresis and staining with ethidium bromide and exposure to uv light.

\section{DNA sequencing}

Double stranded PCR products were sequenced from each of the amplification primers and a number of internal sequencing primers. Approximately $100 \mathrm{ng}$ of cleaned products were sequenced from 3.2 pM of primer using the PRISM Ready Reaction Dye Deoxy Terminator Cycle Sequencing Kit (Applied Biosystems, Foster City, CA). The reaction was carried out in a Perkin Elmer Cetus DNA Thermal Cycler for 25 cycles under the following conditions. Template denaturation was done at $96^{\circ}$ for $30 \mathrm{~s}$, primer annealing at $50^{\circ}$ for $15 \mathrm{~s}$, and primer extension at $60^{\circ}$ for $4 \mathrm{~min}$. The cycle sequencing products were purified of excess dye with filtration through Sephedex G-50 Fine (Pharmacia) columns, and were run on a $4 \%$ polyacrylamide gel in a 373A and 377 Automatic Sequencer (Applied Biosystems). 
Table 2. GenBank accession nos of ribosomal DNA sequences used in phylogenetic analyses.

\begin{tabular}{|c|c|c|c|}
\hline \multirow[b]{2}{*}{ Species } & \multicolumn{3}{|c|}{ GenBank accession no. } \\
\hline & nuSSU & nuITS & nuLSU \\
\hline Clavulina cristata & AF026640 & - & AF261553 \\
\hline Dendrocorticium polygonioides (A) & - & - & AJ406531 \\
\hline D. polygonioides (B) (as Corticium polygonioides) & - & - & U80646 \\
\hline Dendrocorticium roseocarneum & AF334910 & - & AF393053 \\
\hline Duportella tristicula & - & - & U80649 \\
\hline Galzinia incrustans & AF518578 & - & AF518617 \\
\hline Gloeophyllum sepiarium & AJ420946 & - & AF393059 \\
\hline Heliocybe sulcata & AF334915 & - & - \\
\hline Laeticorticium roseum (as Corticium roseum) & - & - & U80647 \\
\hline Marchandiomyces aurantiacus CBS 718.97 & AF289661 & AY583324 & AY 583330 \\
\hline M. corallinus ATCC 200796 & AF289660 & AY583325 & - \\
\hline M. corallinus ATCC MYA 1118 & - & AY583326 & - \\
\hline M. corallinus JL128-98 & - & AY583327 & AY 583331 \\
\hline M. lignicola ATCC MYA 299 & AF289659 & AY 583328 & AY 583332 \\
\hline M. lignicola ATCC MYA 835 & AY583333 & AY583329 & - \\
\hline Punctularia strigosozonata & AF518586 & - & AF518642 \\
\hline Rhizoctonia zeae & D85647 & AF222799 & - \\
\hline Tretopileus sphaerophorus & $\mathrm{AB} 006005$ & - & - \\
\hline Vuilleminia comedes (A) & AF518594 & - & AF518666 \\
\hline V. comedens $(\mathrm{B})$ & - & U52878 & U80665 \\
\hline$V$. comedens $(\mathrm{C})$ & - & U52879 & AJ406515 \\
\hline V. cystidiata Parmasto & - & U52883 & U80666 \\
\hline Waitea circinata $(\mathrm{A})$ & & WCAJ195 & \\
\hline$W . \operatorname{circinata}(\mathrm{B})$ & & WCAJ196 & \\
\hline
\end{tabular}

\section{Sequence compiling}

Base calling software (Sequencing Analysis, ABI Prism, 2.1.1) was used to produce a preliminary nucleotide sequence. The nucleotide sequence fragments were compiled using Sequence Navigator 1.0 (Applied Biosystems). The sequences were confirmed by comparison to sequences produced from the opposite strand, and altered by manual base calling where appropriate.

\section{Phylogenetic analysis}

Maximum parsimony (MP), PAUP 4.0 (Swofford 1998), was used to produce phylogenetic hypotheses from the aligned nucleotide sequences, individually for the three gene regions the nuSSU, nuLSU, and nuITS rDNA regions, and also in combination. GenBank sequences from 18 other basidiomycetes representing 14 species were included in the analysis (Table 2). Two taxa were treated as outgroups for the analysis, Gloeophyllum sepiarium and Heliocybe sulcata. None of the characters was excluded, invariant characters were ignored, and gaps were treated as missing data. Preliminary analyses treating the gaps as new character states did not produce different topologies. All characters were weighted equally and branch lengths equal to zero were collapsed to polytomies. The heuristic analysis was repeated 100 times using random addition. Bootstrap percentages were determined from 200 resamplings of the data set and Jackknife percentages from 200 resamplings for the individual gene regions and from 1000 resamplings for the combined data set.
The gene regions were tested for congruence in a partition homogeneity analysis in PAUP.

For the combined dataset, the equally parsimonious trees (EPTs) were used as starting trees for a maximum likelihood (ML) analysis (PAUP 4.0; Swofford 1998) using the Rogers-Swofford approximation method. The analysis used the General Time Reversible (GTR) model assuming six substitution types with ML estimates of the substitution rates and nucleotide frequencies. The among-site rate variation assumed a ML estimated proportion of invariable sites, and a gamma distribution of variable sites with a ML estimated shape. These settings correspond to the GTR $+\mathrm{G}+\mathrm{I}$ model, the model selected for the aligned sequences by MrModeltest 1.1 (Nylander 2002), a simplified version of Modeltest (Posada \& Crandall 1998). The trees generated in the MP and ML analyses above were compared using the Shimodaira-Hasegawa $(\mathrm{SH})$ tests of topology in PAUP.

Bayesian analysis was performed in MrBayes 3.0b3 (Huelsenback \& Ronquist 2001) using a uniform GTR $+\mathrm{G}+\mathrm{I}$ model, as selected by Akaike Information Criterion (AIC) in MrModeltest (Nylander 2002): $[\mathrm{GTR}+\mathrm{G}+\mathrm{I}]$ lset $\mathrm{nst}=6$ rates $=$ invgamma; prset revmatpr $=$ uniform $(0.0,50.0) \quad$ statefreqpr $=$ dirichlet $(1,1,1,1)$ shapepr $=$ uniform $(0.0,100.0)$ pinvarpr $=$ uniform $(0.0,1.0)$. Two additional GTR $+\mathrm{G}+\mathrm{I}$ models with base frequencies and substitution rates estimated in MrModeltest as prior probabilities, were tested in MrBayes: (1) dirichlet base frequencies and fixed substitution rates: $[\mathrm{GTR}+\mathrm{G}+\mathrm{I}]$ lset $\mathrm{nst}=6$ rates $=$ invgamma; prset revmatpr $=$ fixed $(0.8847,3.6247$, 
$2.6453,0.8048,7.9805,1) \quad$ statefreqpr $=\operatorname{dirichlet}(1,1,1,1)$ shapepr $=$ fixed $(0.4524) \quad$ pinvarpr $=\operatorname{fixed}(0.6687) ;$ and (2) fixed base frequencies and substitution rates: $[\mathrm{GTR}+\mathrm{G}+\mathrm{I}]$ lset $\mathrm{nst}=6$ rates $=$ invgamma; prset revmatpr $=$ fixed $(0.8847,3.6247,2.6453,0.8048,7.9805$, 1) statefreqpr $=$ fixed $(0.2490,0.2137,0.2662,0.2711)$ shapepr $=$ fixed $(0.4524) \quad$ pinvarpr $=$ fixed $(0.6687) . \quad$ All models assumed six substitution types with ML estimates of the nucleotide frequencies and among site rate variation with a proportion of the sites invariable and rates for the remaining sites drawn from a gamma distribution that was ML estimated.

In the MrBayes analysis, best trees were saved and examined from every tenth replicate from the over 600000 replicates in 12 Markov chains, three runs each of four chains. For the over 60000 saved trees, $-\mathrm{Ln}$ likelihoods were examined for convergence on a stable likelihood value over the course of each run. Trees collected before this point were discarded as 'burnin' (Huelsenback \& Ronquist 2001). From around 7000 trees collected for each of the runs, 700 trees were discarded. The remaining trees (57906) were used to build a majority rule consensus tree where the percentage of the retained 'best' trees supporting a branch represents the Bayesian posterior probabilities. Bayesian analysis also found most likely trees that were compared to those from MP and ML analyses.

\section{RESULTS}

\section{Phylogenetic relationships of Marchandiomyces species}

In the present study, two collections from the same locality of an unnamed species of lignicolous fungus were isolated as axenic cultures and compared with cultures from each of three collections of the lichenicolous Marchandiomyces corallinus and one collection of the lichenicolous $M$. aurantiacus (Table 1). These cultures were used for production of nucleotide sequences from three nuclear ribosomal gene regions, nuSSU, nuITS, and nuLSU rDNA. Sequences from the two lignicolous cultures were almost identical (>99.8\%), as were the three cultures of $M$. corallinus (>99.4\%). Sequences from 18 basidiomycetous fungi (Table 2) were selected as potentially related to the Marchandiomyces cultures on the basis of sequence similarities in BLAST searches of GenBank and preliminary phylogenetic analyses of the nu LSU rDNA (data not shown). Although our previous analysis of nuSSU rDNA sequences (Sikaroodi et al. 2001) supported the phylogenetic relationship of Marchandiomyces species to a clade including Rhizoctonia zeae and Tretopileus sphaerophorus, BLAST searches and preliminary phylogenetic analysis additionally suggested the relationships of Marchandiomyces to some representatives of the families Clavulinaceae, Corticiaceae, and Hyphodermataceae. Two species, Gloeophyllum sepiarium of the Gloeophyllaceae and Heliocybe sulcata of the Polyporaceae, were selected as outgroups for the analysis. Since sequences from each of the three regions were not available for all of these taxa and cultures, available sequences were aligned and unavailable gene sequences treated as missing data.

Individually and in combination, the aligned sequences of the two ribosomal genes, nuSSU and nuITS, produced fully congruent phylogenies in parsimony analysis (partition homogeneity test $\mathrm{p}=1$ ). However, aligned sequences from these two gene regions were partially incongruent with those of the nuLSU (partition homogeneity test $p=0.69$ ). Each of the gene regions contributed between 59 and 204 potentially informative characters, and in combination 383, for the matrix of 24 taxa (Table 3). Although the nuITS had one variable region with ambiguous alignment, inclusion/exclusion of these positions did not affect the topology of the tree and they were included in the final analyses. The aligned gene sequences were subjected to phylogenetic analysis singly and in combination using MP, ML, and Bayesian analyses. When gaps were treated as missing data, parsimony analysis found a single most parsimonious tree (MPT) for the nuSSU, three equally parsimonious trees (EPTs) for the nuITS, two EPTs for the nu LSU, and 81 EPTs for the combined analyses of all three genes (Figs $1 \& 2$ ). Treating the gaps as new character states increased the number of steps but did not change the topologies of the Marchandiomyces specimens, except for the nuLSU analysis where $M$. aurantiacus had different sister taxa relationships (data not shown). ML analysis of the combined data set using the GTR $+\mathrm{G}+\mathrm{I}$ model in PAUP (Swofford 1998) found a tree that was more likely ( $-\operatorname{lnL} 9982.0316)$, but not significantly different on the basis of the Shimodaira-Hasegawa test, from those found in parsimony analysis. However, Bayesian analysis in MrBayes (Huelsenback \& Ronquist 2001) under the same model with uniform prior probabilities found a more likely tree (Fig. 3, - $\ln L$ 9981.9475), differing only in the resolution within the sister and basal clades, that was not significantly better than the MP or ML trees in the Shimodaira-Hasegawa test. Bayesian analysis, pooling trees found from the three different prior probabilities, provided significant posterior probabilities $(>95 \%)$ for all of the branches shared with the MP topology (Fig. 3).

Parsimony and likelihood analyses of all of the datasets agreed on the relationships within the Marchandiomyces; the lignicolous specimens formed a sister clade to the unresolved representatives of $M$. corallinus, with the representative of $M$. aurantiacus basal to these taxa (Figs 1-3). The sister clade relationship of the lignicolous specimens and $M$. corallinus was supported at the 99-100\% level in bootstrap, jackknife, and Bayesian analyses. However, the relationship of M. aurantiacus to $M$. corallinus and the lignicolous specimens was problematic. Although most of the analyses show the three species of Marchandiomyces as monophyletic (for example analysis of nuSSU, Fig. 1A), this relationship should be considered ambiguous at this point 
Table 3. Results from maximum parsimony analysis of nuSSU, ITS, and nuLSU rDNA, individually and in combination, for taxa sets (as in Figs 1-2).

\begin{tabular}{|c|c|c|c|c|}
\hline & nuSSU & ITS & nuLSU & Combined \\
\hline No. of taxa & 13 & 12 & 16 & 24 \\
\hline Length of alignment (bp) & 2009 & 664 & 1026 & 3699 \\
\hline $\begin{array}{l}\text { No. variable, parsimony } \\
\text { uninformative characters }\end{array}$ & 65 & 52 & 122 & 239 \\
\hline $\begin{array}{l}\text { No. variable, parsimony } \\
\text { informative characters }\end{array}$ & 59 & 204 & 120 & 383 \\
\hline No. constant characters & 1885 & 408 & 784 & 3077 \\
\hline \multicolumn{5}{|c|}{ Gaps as missing character states: } \\
\hline No. MPT & 1 & 3 & 2 & 81 \\
\hline Tree length (steps) & 187 & 382 & $436^{*}$ & 1017 \\
\hline $\mathrm{CI}$ & 0.73 & 0.88 & 0.69 & 0.76 \\
\hline $\mathrm{HI}$ & 0.27 & 0.12 & 0.31 & 0.24 \\
\hline RI & 0.66 & 0.91 & 0.58 & 0.75 \\
\hline $\mathrm{RC}$ & 0.48 & 0.80 & 0.40 & 0.57 \\
\hline$-\operatorname{lnL}(\mathrm{GTR}+\mathrm{I}+\mathrm{G})$ & 3652.1380 & 2427.1140 & 3506.9149 & 10021.5173 \\
\hline \multicolumn{5}{|l|}{ Gaps as new character states: } \\
\hline No. MPTs & 1 & 3 & 1 & 1024 \\
\hline Tree length (steps) & 198 & 673 & $604 *$ & 1521 \\
\hline \multicolumn{5}{|l|}{ ML tree } \\
\hline$-\ln \mathrm{L}(\mathrm{GTR}+\mathrm{I}+\mathrm{G})$ & 3646.1739 & 2427.1140 & $3505.3685^{*}$ & 9981.9475 \\
\hline
\end{tabular}

* Marchandiomyces species polyphyletic.

since it is not supported with significant Bayesian posterior probabilities combined with high bootstrap and jackknife values (Figs 2-3). Only analysis of the nuITS gene showed significant bootstrap (78\%) and jackknife (80\%) support for the genus (Fig. 1B). Analysis of the nuLSU gene produced a polyphyletic Marchandiomyces in all types of analysis, maximum parsimony, maximum likelihood, and Bayesian (Fig. 1C-D). In parsimony analysis, only two additional steps were required to produce a monophyletic Marchandiomyces.

In the analysis of nuSSU, nuITS, and the combined genes, the well supported (Bayesian posterior probability of $95 \%$, Figs $1 \mathrm{~A}-\mathrm{B}, 2-3$ ) sister clade to the Marchandiomyces included Galzinia incrustans, Tretopileus sphaerophorus, and Rhizoctonia zeae and its teleomorph Waitea circinata. In contrast, the analysis of nuLSU $M$. corallinus and the lignicolous marchandiomyces-like culture were either a sister taxon to M. aurantiacus and G. incrustans (Fig. 1D, Bayesian analysis) or to a poorly supported clade of G. incrustans and some species of the Corticiaceae, Vuilleminia comedens, Duportella tristicula and Laeticorticium roseum, with $M$. aurantiacus basal to this group (Fig. 1C, maximum parsimony and likelihood analysis). In all analyses except with nuLSU, a poorly supported clade (Fig. 3, Bayesian posterior probability $27 \%$ ) or grade was basal to Marchandiomyces and its Galzinia-Waitea sister clade. Within this assemblage three clades had significant support: (1) a clade of Dendrocorticium roseocarenum, D. polygonioides, Punctularia strigosozonata, and $V$. cystidiata (Bayesian posterior probability $100 \%$ ); (2) a clade of $V$. comedens samples (Bayesian posterior probability $100 \%$ ), and
(3) a clade of Duportella tristicula and Laeticorticium roseum (Bayesian posterior probability 97\%). Clavulina cristata (Clavulinaceae) along with the outgroups Gloeophyllum sepiarium (Gloeophyllaceae) and Heliocybe sulcata (Polyporaceae) were basal to the entire in-group clade.

Given the strong support (100\% Bayesian posterior probabilities) for a monophyletic relationship between the lignicolous specimens and Marchandiomyces corallinus, the type of the genus, and $M$. aurantiacus, we describe these specimens as a new species of Marchandiomyces. Since the lignicolous specimens were collected from the same locality, are nearly identical in ribosomal sequences and similar in morphology, we recognize them as members of the single new species $M$. lignicola.

\section{Comparison of the known species of Marchandiomyces}

Of the three species of Marchandiomyces, M. lignicola has much smaller sclerotia $(30-50 \mu \mathrm{m}$ diam, Fig. 6) than those of $M$. aurantiacus and $M$. corallinus. The sclerotia of $M$. lignicola and $M$. corallinus share the same pinkish colour and are immersed during early stages of development, while those of $M$. aurantiacus are orange and superficial throughout development. Microscopically, the sclerotia of both M. aurantiacus and $M$. corallinus are composed of large, subspherical to elongate, catenate cells (best seen in squash preparations; Fig. 5), while the cells in M. lignicola are radiating, branched, typically bi- or trifurcate and apically swollen (Figs 2-5). M. lignicola grows exclusively on dead wood, while the two other species are virulent lichen parasites. 
(A)

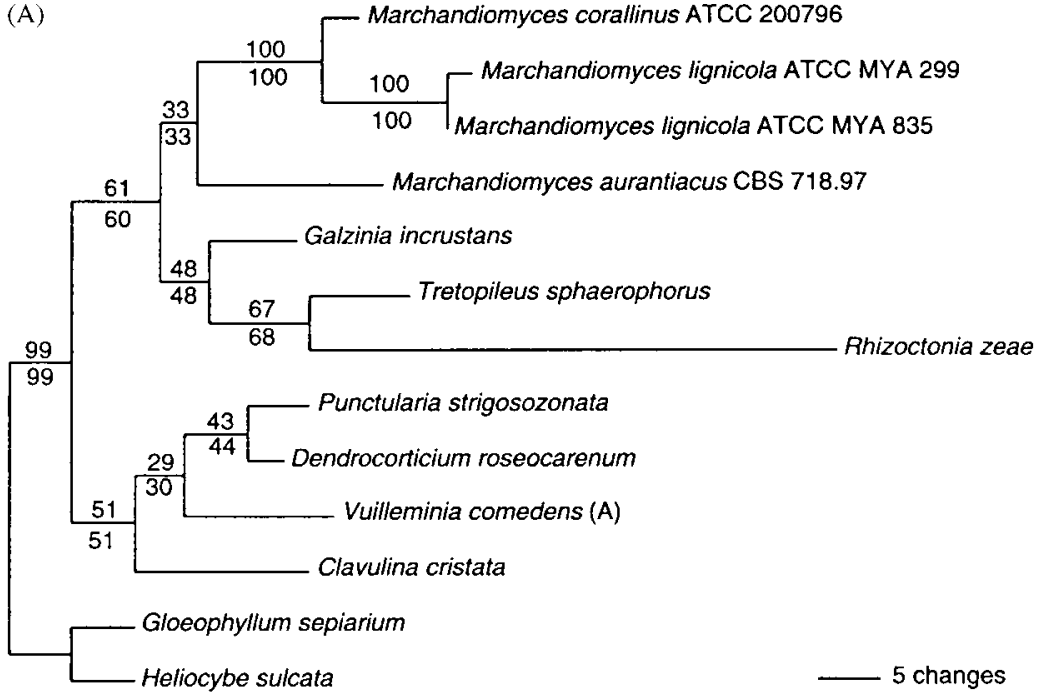

(C)

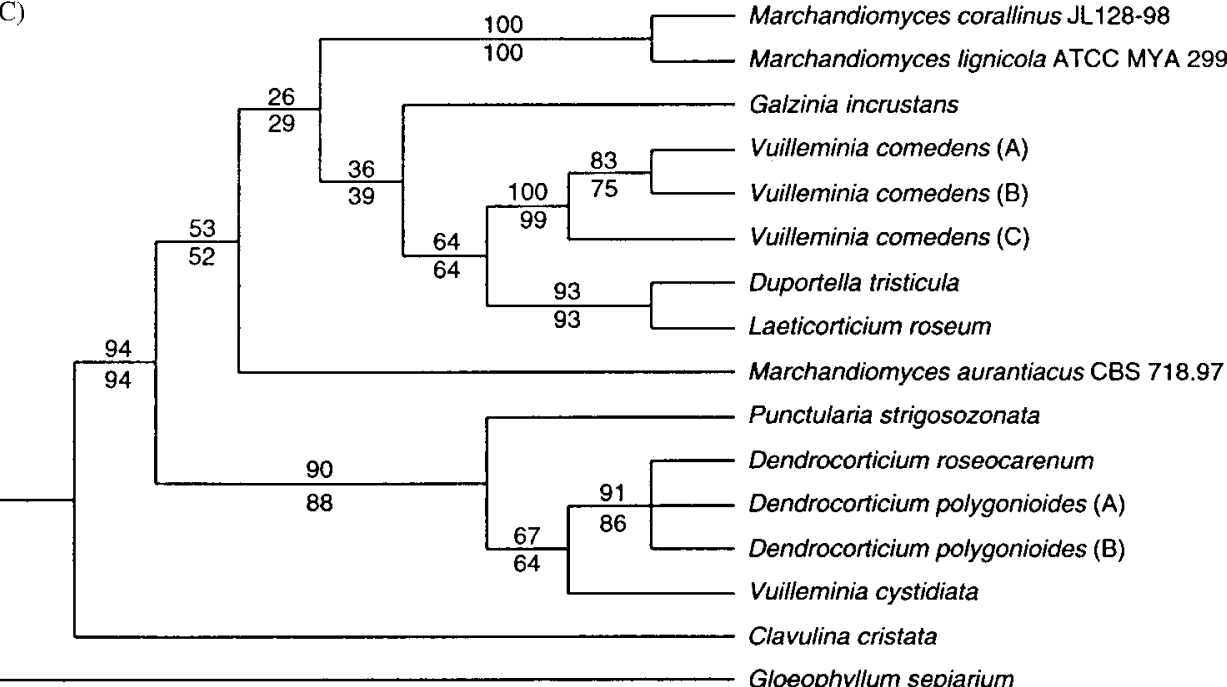

(B)

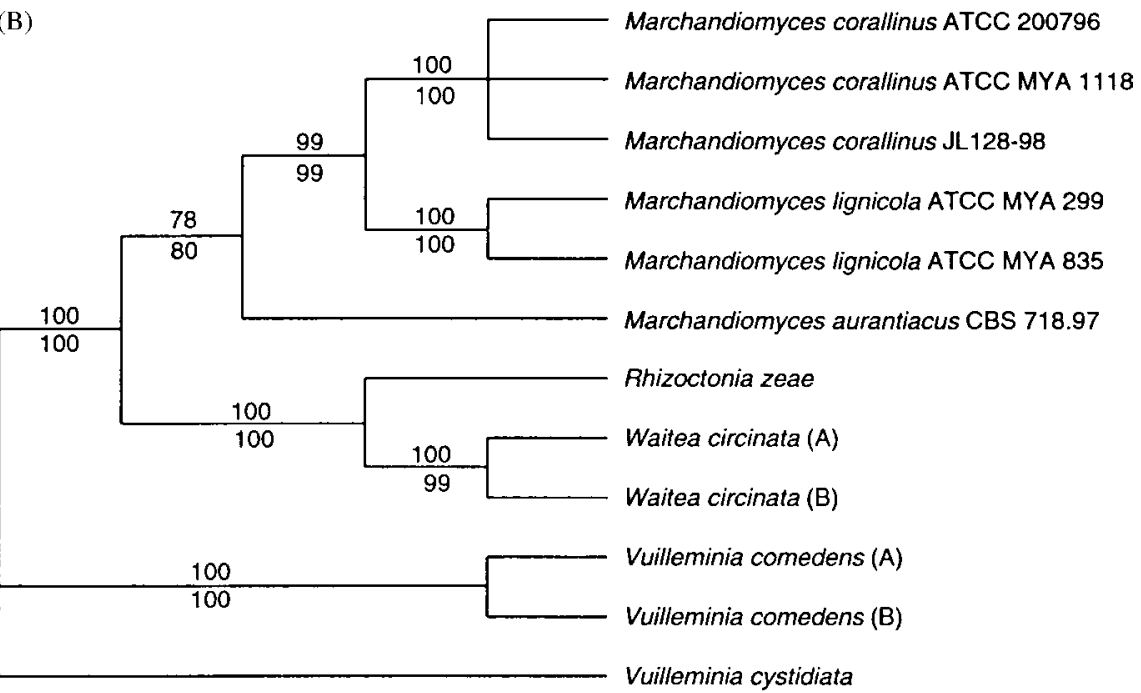

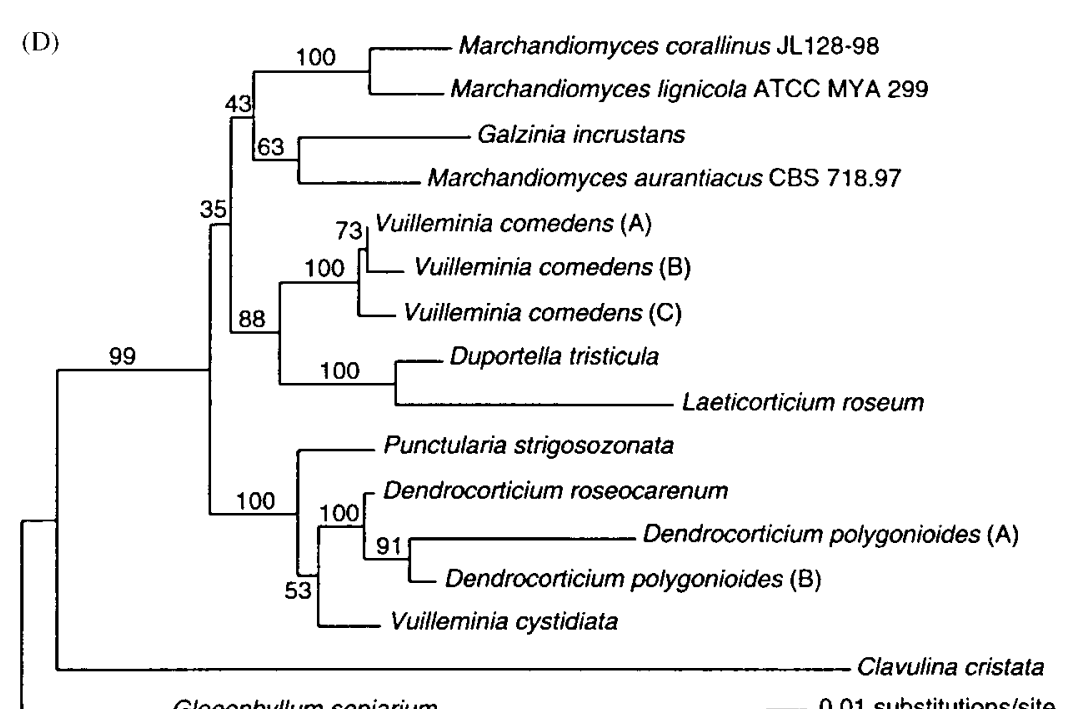

Gloeophyllum sepiarium
- 0.01 substitutions/site

Fig. 1. Phylogenetic relationships of the lignicolous Marchandiomyces lignicola to lichenicolous Marchandiomyces species and representative basidiomycetous fungi, as derived from independent parsimony analysis of three nuclear rDNA gene regions. (A) Most parsimonious tree (MPT) found in analysis of aligned nuSSU rDNA sequences from 13 basidiomycetous specimens. (B) Strict consensus of three equally parsimonious trees (EPTs) found in analysis of aligned nuITS rDNA sequences from 12 specimens. (C) Strict consensus of two EPTs found in analysis of aligned nuLSU rDNA sequences from 16 specimens. (D) Consensus tree found in bayesian analysis of aligned nuLSU rDNA sequences from 12 specimens. For A, B, and C, bootstrap and jacknife values (\%) from 200 resampling are shown for each branch, above and below the branch, respectively. For D, Bayesian posterior probabilities from sampling of 19700 trees are shown for each branch. See Table 3 for details of the analyses. 


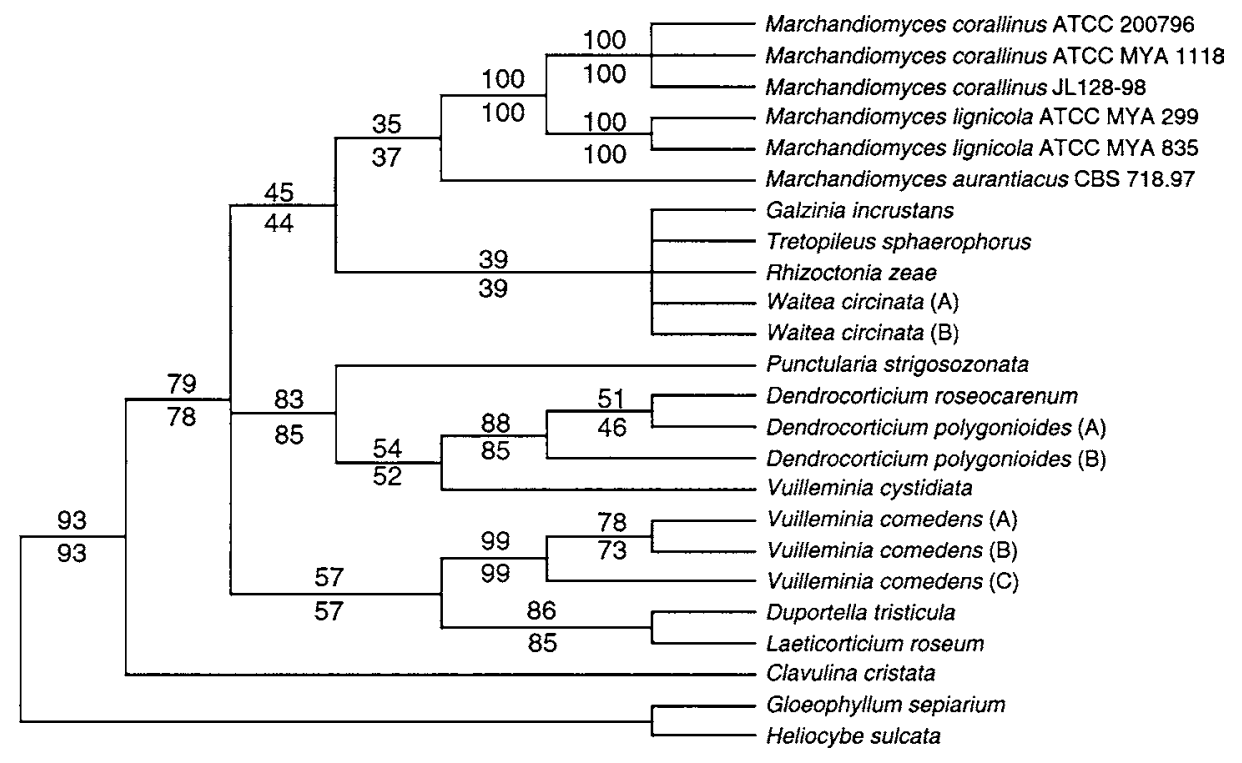

Fig. 2. Phylogenetic relationships of the lignicolous Marchandiomyces lignicola to lichenicolous Marchandiomyces species and representative basidiomycetous fungi, as derived from parsimony analysis of a combined alignment of the three gene regions, nuSSU, ITS and nuLSU. Shown is the strict consensus of 81 EPTs found from analysis of aligned rDNA sequences from 24 specimens. Bootstrap and jacknife values (\%) from 1000 resampling are shown for each branch, above and below the branch, respectively. See Table 3 for details of the analyses.

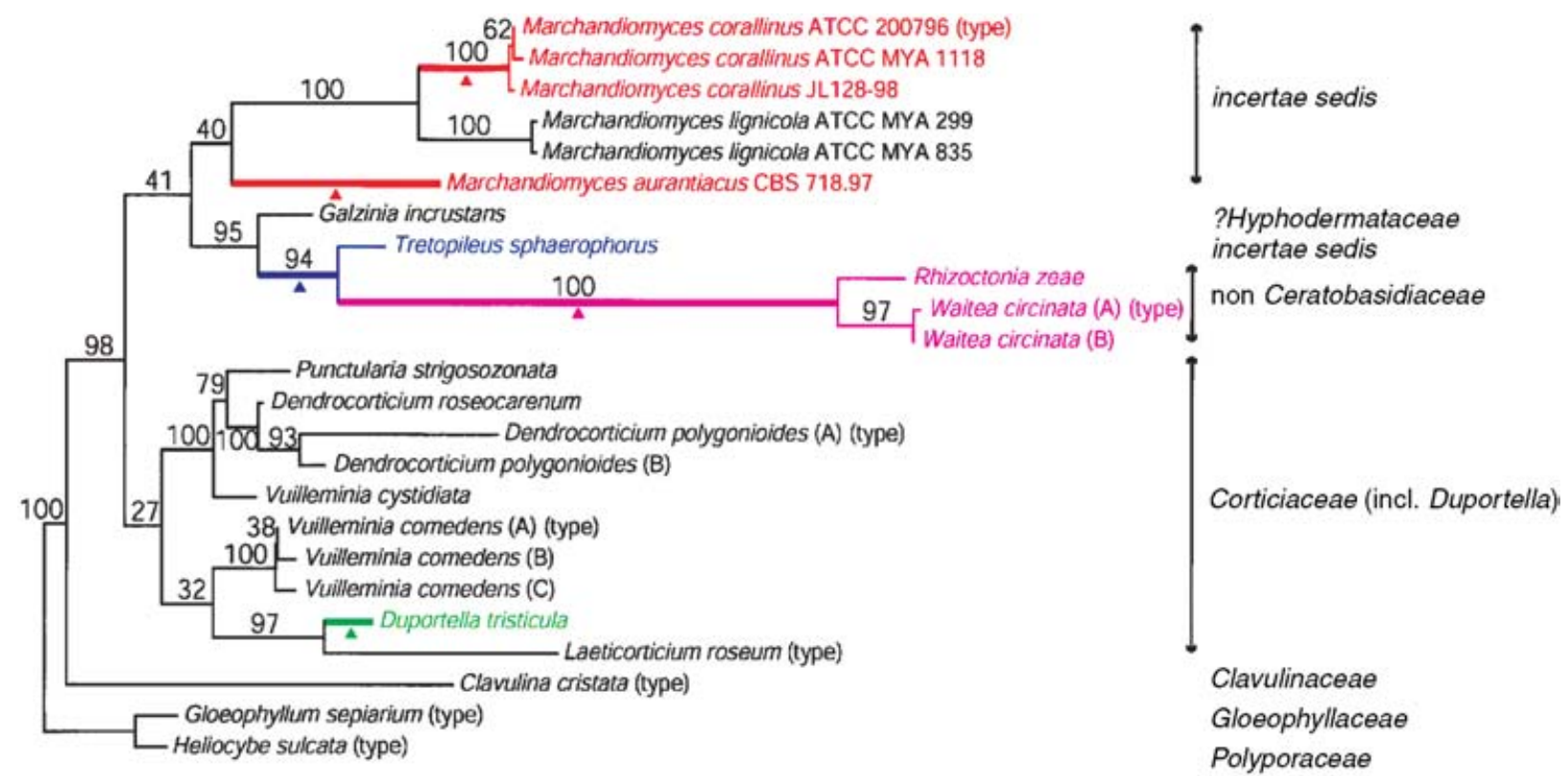

Herbicolous

Lichenicolous

Lignicolous

Phytopathogenic/Saprobic

Saprobic

- 0.01 substitutions/site

Fig. 3. Parallel origin of the lichenicolous habit in Marchandiomyces from the ancestral lignicolous habit. Shown is the most likely tree, and Bayesian consensus tree (- Ln likelihood 10629.21503), found in Bayesian analysis of a combined alignment of three nuclear rDNA gene regions, nuSSU, ITS and nuLSU. Herbicolous (green), lichenicolous (red), lignicolous (black), phytopathogenic/saprobic (magenta), and saprobic (blue). Reconstruction of five changes in habit is indicated by colored triangles $(\boldsymbol{\Delta})$. Two branches where it is both most likely and most parsimonious that the ancestral lignicolous habit changed to lichenicolous are indicated by red triangles. Current classification to family for each taxon is indicated on the right with specimens that represent the type species of the genus indicated by (type). 


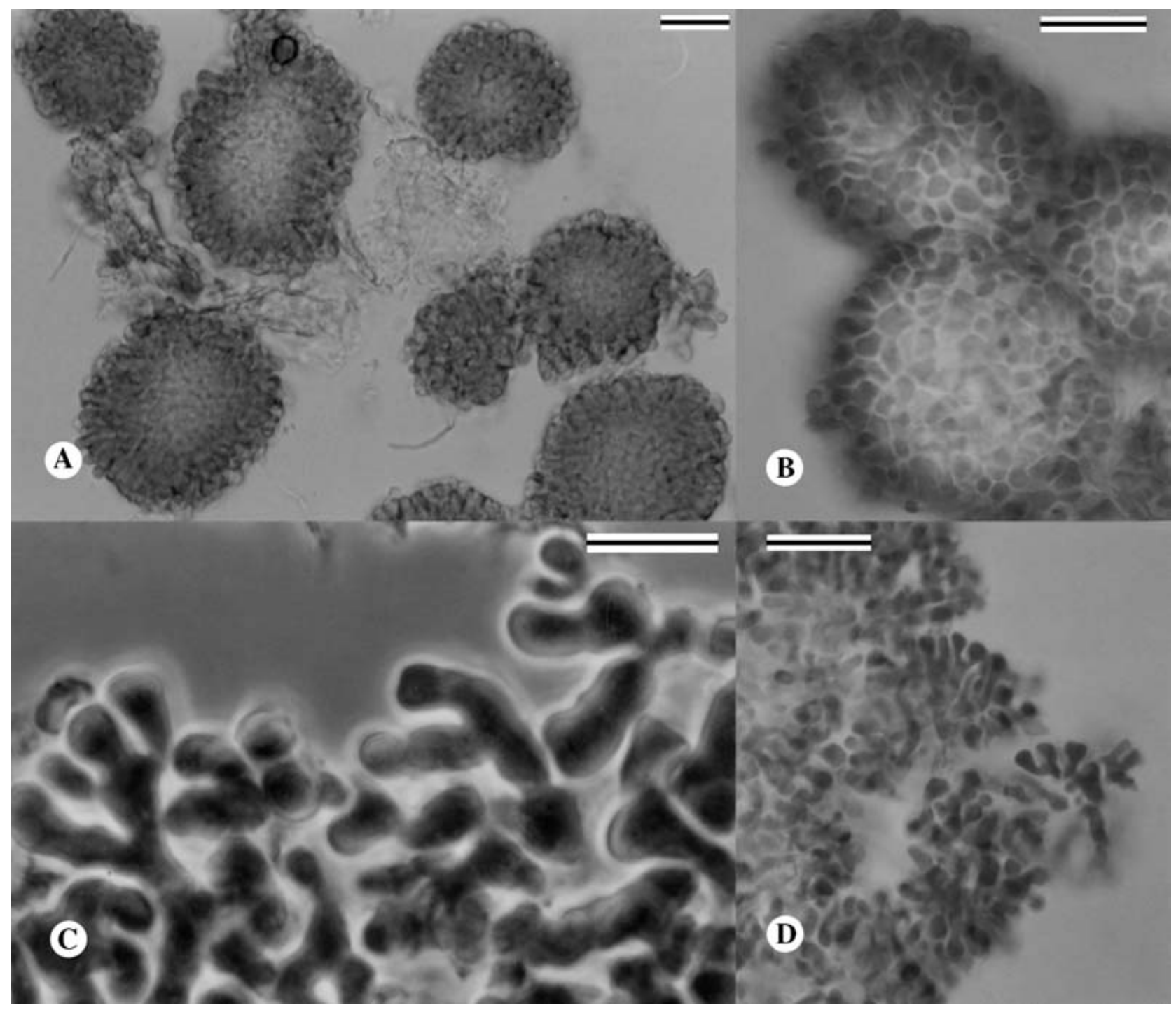

Fig. 4. Marchandiomyces lignicola (holotype). (A) Sclerotia in optical section (in Congo red). (B) Sclerotia, surface view (in LCB, the stain only penetrated the external cells of the sclerotium). (C) Squash preparation of sclerotia (in Congo red, with phase contrast). (D) Squash preparation of sclerotia (in LCB). Bars: A, B and D=20 $\mu \mathrm{m}$; C $=10 \mu \mathrm{m}$.

\section{TAXONOMY}

\section{Marchandiomyces lignicola Lawrey \& Diederich,} sp. nov.

Etym: lignicola, growing on wood.

Marchandiomyces species insignis sclerotiis lignicolis, minusculis, subsphericis, corallinis, 30-50 $\mu \mathrm{m}$ diam, hyphis radiatis, ramosis, raro septatis, pariete tenui et laevi, hyalinis, 2-2.5 um diam, apicaliter tumidis, 2-3-furcatis, usque ad $6 \mu \mathrm{m}$ diam.

Typus: USA: Virginia: Rappahannock Co.: Aaron Mt, mixed oak stand, decorticated dead Quercus branch on ground, 16 Jan. 1999, J. D. Lawrey 1716 (NY - holotypus; herb. Diederich - isotypus; cultura viva ATCC MYA-835).

Basidiomata and conidiomata unknown. Sclerotia lignicolous, at first partly to almost completely immersed, becoming superficial, densely covering the substratum, often touching each other laterally, subspherical, extremely small, 30-50 um diam, pastel red (Kornerup \& Wanscher 1984: 8A4-5), macroscopically appearing as pinkish areas of several $\mathrm{cm}$ diam; sclerotia composed of radially orientated, frequently branched and rarely septate, thin-walled, smooth, hyaline hyphae $2-2.5 \mu \mathrm{m}$ wide, which are typically bi- or trifurcate and apically swollen, up to $6 \mu \mathrm{m}$ wide. In liquid culture, pinkish mycelium forming spherical masses of $1-2 \mathrm{~cm}$ diam and rarely erupting to the surface. Hyphae of cultured mycelium exhibit obvious clamps. No growth on maltose, good growth on various commercial media that contain dextrose (Sabouraud's medium with dextrose is used for routine culture).

Additional specimens examined: USA: Virginia; Rappahannock Co.: Aaron Mt, on decorticated dead Quercus branches, Dec. 1997, J. D. Lawrey 1645 (herb. Diederich), 1636 (US, ATCC MYA-299); Jan. 1999, J. D. Lawrey 1714, 1721 (US), 1731 (herb. Diederich). 


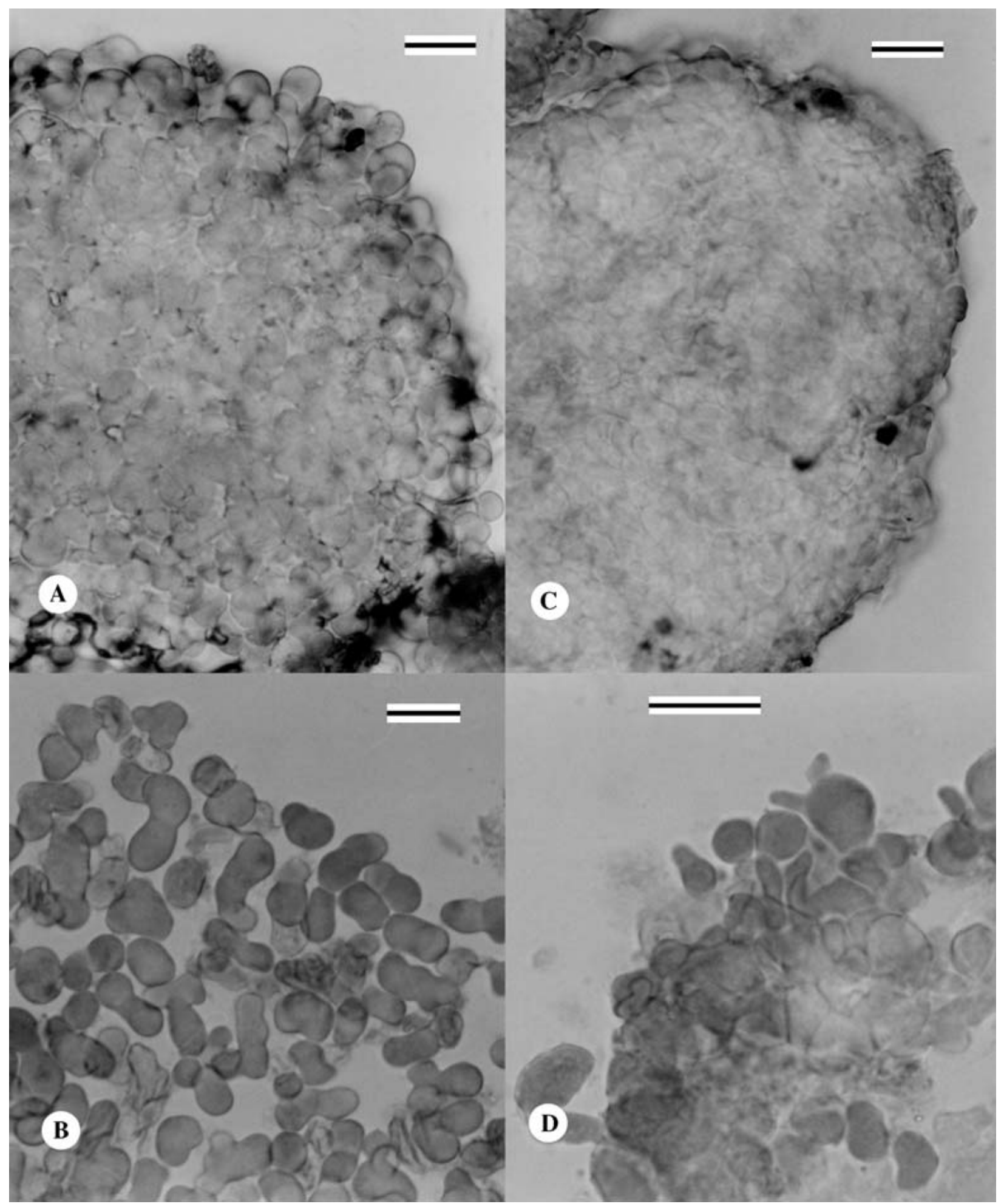

Fig. 5. (A) Marchandiomyces aurantiacus (Diederich 13745), sclerotium in optical section (in Congo red); and (B) as A, squash preparation. (C) M. corallinus (Diederich 13629), sclerotium in optical section (in Congo red); (D) idem, squash preparation. Bars $=20 \mu \mathrm{m}$.

\section{DISCUSSION}

The genus Marchandiomyces was introduced by Diederich \& Hawksworth (in Diederich 1996) for the lichenicolous hyphomycete previously known as Illosporium corallinum. Careful field studies and subsequent examination of type material led Etayo \& Diederich (1996) to accept the existence of at least two species, M. aurantiacus with orange fruit bodies, and $M$. corallinus with pinkish ones. In herbarium material of both species, the bright colour often disappears within a few years, and their identification 


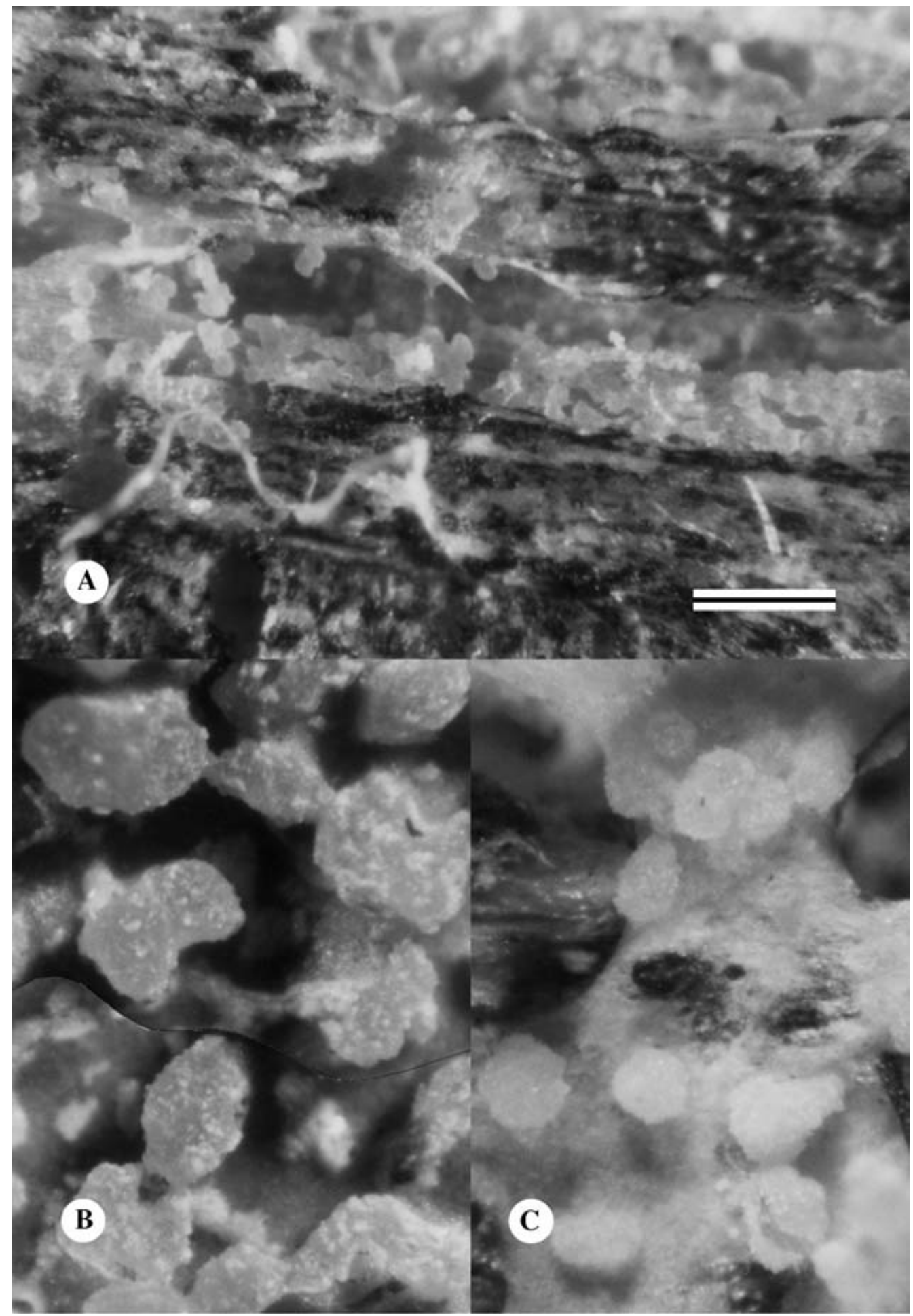

Fig. 6. Sclerotia of Marchandiomyces spp. (A) Marchandiomyces lignicola (holotype). (B) M. corallinus (Belgium: Lischert, on Parmelia saxatilis, D. Thoen, hb. Diederich). (C) M. aurantiacus (Luxembourg: Mersch, on Physcia tenella, Diederich 13745). Bar $=250 \mu \mathrm{m}$ (applies to A-C).

then becomes difficult. Lowen et al. (1986) noticed that Illosporiopsis christiansenii (syn. Hobsonia christiansenii) has a similar, if not identical, pink pigment as M. corallinus, and they postulated that both $M$. corallinus and $I$. christiansenii might be synanamorphs of the same fungal species. This was contradicted by the recent discovery that Marchandiomyces is basidiomycetous, while $I$. christiansenii is ascomycetous (Sikaroodi et al. 2001). M. corallinus has dolipore septa and septal pore caps similar to those of the Ceratobasidiales, and M. aurantiacus (teleomorph Marchandiobasidium aurantiacum) has basidiomata similar to those of the ceratobasidialean Waitea (Diederich et al. 2003). Basidiomata observed in previous studies in 

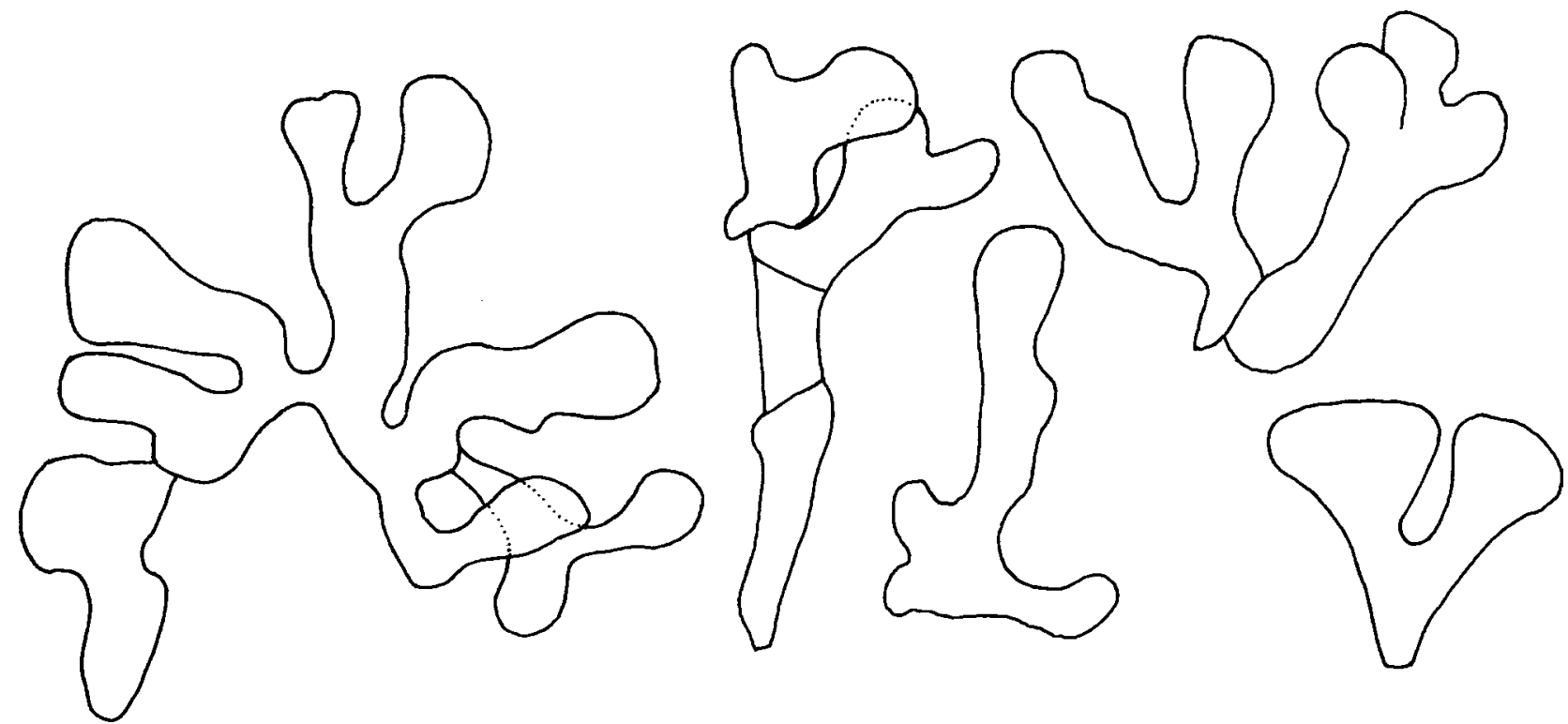

Fig. 7. Marchandiomyces lignicola (holotype), radiating hyphae in a squash preparation. Bar $=10 \mu \mathrm{m}$.

an immature stage were incorrectly interpreted as 'sporodochia'.

On the basis of the present analysis, the three species of Marchandiomyces were included in a significantlysupported clade comprising representatives of the type species of Dendrocorticium (D. roseocarneum) and Duportella (D. tristicula, syn. D. velutina), Laeticorticium (L. roseum), Vuilleminia (V.comedens), and Waitea ( $W$. circinata), in addition to the type of Marchandiomyces (M. corallinus). The clade also contained species placed in genera Galzinia, Tretopileus, and Punctularia. Many of these genera, Dendrocorticium, Duportella, Laeticorticium, and Vuilleminia, are members of a Corticiaceae clade that Hallenberg \& Parmasto (1998) referred to as a 'suprageneric taxon'. The latter study also included the species Cytidia salicina in this clade; however, in our preliminary analyses (data not shown) the sequence that referred to this species produced instability in the topology and reduced resolution within the clade, and it was excluded from our final analyses. On the basis of these analyses, Punctularia strigosozonata is monophyletic with Dendrocorticium species and $V$. cytstidiata. Vuilleminia, as currently circumscribed, appears polyphyletic as reported in Hallenberg \& Parmasto (1998), with $V$. cystidiata phylogenetically separated from $V$. comedens (the type of the genus). The members of this 'supergeneric taxon' are lignicolous, with the exception of the herbicolous habit of the tropical Duportella tristicula that is newly derived on the basis of its sister taxon relationship to the lignicolous Laeticorticium roseum.

In contrast to the lignicolous Corticiaceae, the anamorph Rhizoctonia zeae and its teleomorph Waitea circinata are soil-borne saprobes and pathogens of cereals, turf grasses and legumes, especially causing sheath spot and root rot of rice and corn. The polyphyletic species of Rhizoctonia, characterized by their common hyphal anatomy, are proposed to have affinities with many diverse families, the basidiomycetous Ceratobasidiaceae and Corticiaceae, and even the ascomycetous Otideaceae (Kirk et al. 2001). In this analysis, $R$. zeae and $W$. circinata formed a wellsupported sister clade to the saprobe Tretopileus sphaerophorus, an anamorph earlier thought to be ascomycetous, and Galzinia incrustans, a lignicolous species placed in the Hyphodermataceae. Although the clade has significant posterior probabilities in Bayesian analysis, 95\%, it has ambiguous support in bootstrap and jackknife analyses (39\% in each) and exceptionally-long internal branch lengths in maximum likelihood phylograms (0.11 substitutions/site; see Fig. 3).

Waitea, along with Ceratobasidium and Thanatephorus were included in the Ceratobasidiales and Ceratobasidiaceae by Roberts (1999). In contrast, in our multigene region analyses (results not shown), Waitea circinata and Rhizoctonia zeae are unrelated to Ceratobasidium, Thanatephorus, or R. solani, and not closely related to a clade containing Ganoderma, Phanerochaete, Spongipellis, and Trichaptum as we previously proposed with nuSSU data alone (Sikaroodi et al. 2001). Instead, they have affinities with the Corticaceae. $R$. zeae and $W$. circinata share with the Marchandiomyces species a pinkish to buff colour in cultures and sclerotia (as do some Corticiaceae), with $M$. corallinus the same dolipore septal ultrastructure, and with $M$. aurantiacus (teleomorph Marchandiobasidium aurantiacum) similar basidiome characters (Diederich et al. 2003). However, the relative relationships of the three Marchandiomyces species to Waitea, also suggested by Diederich et al. (2003), and the lignicolous Corticiaceae cannot be resolved at the present time because nuSSU, nuITS, and nuLSU sequences are not available from all representatives of these two groups. Most likely Marchandiomyces, R. zeae, and 
Waitea should be placed at least temporarily in the Corticiaceae as they are not phylogenetically related (results not shown), or even morphologically similar (Diederich et al. 2003) to Ceratobasidiaceae as defined by its type species $C$. calosporum. However, it is apparent from recent phylogenetic studies (Hibbett \& Thorn 2001, Larsson, Larsson \& Köljalg 2004) that the corticioid fungi are distributed among many homobasidiomycete groups, so the Corticiaceae (and likely the Ceratobasidiaceae as well) represent grade-level groupings and not families in a phylogenetic sense.

The new species Marchandiomyces lignicola appears to be more closely related to $M$. corallinus than to $M$. aurantiacus. M. aurantiacus differs equally in nucleotide substitutions from $M$. corallinus and M. lignicola, approximately $6 \%$ of the nucleotide positions across the three gene regions, and its placement in the genus is not strongly supported in any of the analyses. It is possible that future sequencing will identify other fungi that are more closely related to $M$. aurantiacus, requiring a new circumscription of the genus Marchandiomyces to make it monophyletic. In classical taxonomy, M. lignicola would almost surely have been placed in a different genus, based on the above differences in nutritional mode, morphology, and anatomy. However, molecular data demonstrate that the habitat differences are of a minor taxonomic importance, and at least $M$. corallinus and $M$. lignicola are congeneric. Originally Marchandiomyces was described as a lichenicolous genus; now we must amend this concept to include a lignicolous species. All of this illustrates the usefulness of molecular data in the taxonomy of sclerotial fungi that have not yet been connected to teleomorphic genera. Sclerotia are not always reliable taxonomic characters at the genus level since sclerotia of non-related species might be quite similar, while those of closely related species can be very different.

In Marchandiomyces, either the lichenicolous habit arose in parallel in $M$. aurantiacus and $M$. corallinus, or it was lost in the $M$. lignicola lineage. When lichenicolous and lignicolous habits are mapped onto the phylogeny, the lignicolous one is observed in all sister clades to be the ancestral state (Fig. 3). With parsimony reconstructions using accelerated transformation (ACCTRAN) or delayed transformation (DELTRAN) character-state optimization or any ML reconstruction, the lichenicolous habit appears to have been gained independently in $M$. corallinus and M. aurantiacus. Nonetheless, phylogenetic analysis alone is insufficient to determine whether or not the lichenicolous habit, or even pre-adaptation to the lichenicolous habit, was a shared characteristic in Marchandiomyces. It would be of interest to determine if differences in cell wall-degrading enzymes or tolerance of lichen extrolites help to explain ecological differences among the three species. However, since the two substrates are so different, modification of degradative enzymes would have had to take place in either case.
The apparent transitions between lignicolous and lichenicolous habits, and among lignicolous and saprobic/phytopathogenic or herbicolous habits, demonstrates the evolutionary flexibility of nutritional modes in these fungi. There would appear to be limitless opportunities for such transitions. In the case of the basidiomycete group Marchandiomyces, the lichenicolous habit most likely arose from a lignicolous ancestor more than once, and may in the future give rise to the lignicolous habit again. Therefore, it would appear that a lichenicolous habit is but one of many ecological habits repeatedly explored by opportunistic fungi.

\section{ACKNOWLEDGMENTS}

Supported by NSF PEET grant (DEB-9712484) to P.T.D. The authors thank Toen Boekhout for providing a culture of Marchandiomyces aurantiacus, and Mariette S. Cole for providing a specimen of M. corallinus. Rosalind Lowen, David L. Hawksworth, Meredith Blackwell, David Hibbett, Martin Grube, and anonymous reviewers provided insightful discussions.

\section{REFERENCES}

Diederich, P. (1990) New or interesting lichenicolous fungi. 1. Species from Luxembourg. Mycotaxon 37: 297-330.

Diederich, P. (1996) The lichenicolous heterobasidiomycetes. Bibliotheca Lichenologia 61 : 1-198.

Diederich, P., Schultheis, B. \& Blackwell, M. (2003) Marchandiobasidium aurantiacum gen. et sp. nov., the teleomorph of Marchandiomyces aurantiacus (Basidiomycota, Ceratobasidiales). Mycological Research 107: 523-527.

Etayo, J. \& Diederich, P. (1996) Lichenicolous fungi from the western Pyrenees, France and Spain. II. More deuteromycetes. Mycotaxon 60: $415-428$.

Gargas, A., DePriest, P. T., Grube, M. \& Tehler, A. (1995) Multiple origins of lichen symbioses in fungi suggested by SSU rDNA phylogeny. Science 268: 1492-1495.

Georgiev, O. I., Nikolaev, N. \& Hadjiolov, A. A. (1981) The structure of yeast ribosomal RNA genes. Complete sequence of the 25S rRNA gene from Saccharomyces cerevisiae. Nucleic Acid Research 9: 6953-6958.

Grube, M., DePriest, P. T., Gargas, A. \& Hafellner, J. (1995) DNA isolation from lichen forming ascomata. Mycological Research 99: 1321-1324.

Hallenberg, N. \& Parmasto, E. (1998) Phylogenetic studies in species of Corticiaceae growing on branches. Mycologia 90: 640-654.

Hawksworth, D. L. (1978) The taxonomy of lichen-forming fungi, reflections on some fundamental problems In Essays in Plant Taxonomy (H. E. Street, ed.): 211-243. Academic Press, London.

Hawksworth, D. L. (1982a) Secondary fungi in lichen symbioses: parasites, saprophytes and parasymbionts. Journal of the Hattori Botanical Laboratory 52: 357-366.

Hawksworth, D. L. (1982b) Co-evolution and the detection of ancestry in lichens. Journal of the Hattori Botanical Laboratory 52: 323-329.

Hawksworth, D. L. (1988a) The variety of fungal-algal symbioses, their evolutionary significance, and the nature of lichens. Botanical Journal of the Linnean Society 96: 3-20.

Hawksworth, D. L. (1988b) Coevolution of fungi with algae and cyanobacteria in lichen symbioses. In Coevolution of Fungi with Plants and Animals (K. A. Pirozynski \& D. L. Hawksworth, eds): 125-148. Academic Press, London. 
Hibbett, D. S., Gilbert, L. B. \& Donoghue, M. J. (2000) Evolutionary instability of ectomycorrhizal symbioses in basidiomycetes. Nature 407: 506-508.

Hibbett, D. S. \& Thorn, R. G. (2001) Basidiomycota: Homobasidiomycetes. In The Mycota. Vol. VII. Part B, Systematics and Evolution (D. J. McLaughlin, E. G. McLaughlin \& P. A. Lemke, eds): 121-168. Springer Verlag, New York.

Huelsenbeck, J. P. \& Ronquist, F. R. (2001) MRBAYES: Bayesian inference of phylogeny. Biometrics. Bioinformatics 17: 754-755.

Kirk, P. M., Cannon, P. F., David, J. C. \& Stalpers, J. A. (2001) Ainsworth \& Bisby's Dictionary of the Fungi. 9th edn. CAB International, Wallingford.

Kornerup, A. \& Wanscher, J. H. (1984) Methuen Handbook of Colour. 3rd edn. Methuen, London.

Larsson, K.-L., Larsson, E. \& Köljalg, U. (2004) High phylogenetic diversity among corticioid homobasidiomycetes. Mycological Research 108: 983-1002.

Lawrey, J. D. \& Diederich, P. (2003) Lichenicolous fungi: interactions, evolution and biodiversity. Bryologist 106: 80-120.

Lowen, R., Brady, B. L., Hawksworth, D. L. \& Patterson, R. R. M. (1986) Two new lichenicolous species of Hobsonia. Mycologia 78: $842-846$.
Lutzoni, F., Pagel, M. \& Reeb, V. (2001) Major fungal lineages are derived from lichen symbiotic ancestors. Nature 411: 937-940.

Mankin, A. S., Skryabin, K. G. \& Rubtsov, P. M. (1986) Identification of ten additional nucleotides in the primary structure of yeast rDNA. Gene 44: 143-145.

Nylander, A. A. (2002) MrModeltest 1.1b. http://www.ebc.uu.se/ systzoo/staff/nylander.html.

Posada, D. \& Crandall, K. A. (1998) MODELTEST: testing the model of DNA substitution. Bioinformatics 14: 817-818.

Roberts, P. (1999) Rhizoctonia-forming fungi: a taxonomic guide. Royal Botanic Gardens, Kew.

Rubtsov, P. M., Musakhano, M. M., Zakharyev, V. M., Krayev, A. S., Skryabin, K. G. \& Bayev, A. A. (1980) Nucleic Acid Research 8: 5779-5794.

Sikaroodi, M., Lawrey, J. D., Hawksworth, D. L. \& DePriest, P. T. (2001) The phylogenetic position of selected lichenicolous fungi: Hobsonia, Illosporium and Marchandiomyces. Mycological Research 105: 453-460.

Swofford, D. L. (1998) PAUP: phylogenetic analysis using parsimony. Version 4.0. Sinauer Associates, Sunderland, MA.

Corresponding Editor: M. Grube 